\title{
La producción social del mercado del sexo y de la ocupación de trabajadoras sexuales en España
}

\author{
The Social Production of the Sex Market and of the \\ Occupation of Sexual Workers in Spain
}

\author{
Teodora Hurtado Saa*
}

Universidad de Guanajuato

\begin{abstract}
RESUMEN
La interseccionalidad de género, etnia/raza, clase, lugar de origen, orientación y prácticas sexuales interviene en la moderna producción social del mercado del sexo y en la construcción de la ocupación de las trabajadoras sexuales. Este artículo da cuenta de la anterior situación a partir del caso de mujeres afrocolombianas y de otras mujeres inmigrantes que laboran en la industria del sexo en España, mostrando cómo estos elementos favorecen la segmentación socioocupacional en los lugares donde ejercen su trabajo. Para comprender esta realidad, incorporamos en el análisis la perspectiva de las trabajadoras y de otros actores sociales e institucionales involucrados.
\end{abstract}

Palabras clave: interseccionalidad, construcción social de la ocupación y mercados de trabajos sexuales, mujeres afrocolombianas, migración.

\begin{abstract}
The intersectionality of gender, ethnicity/ race, class, place of origin, sexual orientation and practices intervenes in the modern social production of the sex market and in the construction of sex workers' occupation. Based on the case of Afro-Colombian women and other immigrant women working in the sex industry in Spain, this article provides an account of the previous situation, showing how these elements favor socio-occupational segmentation in the places where they work. To understand this reality, in the analysis we incorporate the perspective of the workers and of other social and institutional actors involved.
\end{abstract}

Keywords: intersectionality, social construction of the occupation and sex work markets, Afro-Colombian women, migration.

Doctora en Estudios Sociales de la Universidad Autónoma Metropolitana (UAM), sede Iztapalapa. Profesora e investigadora de la Universidad de Guanajuato, Campus León. Su publicación más reciente es: "Por una vida libre de violencia. Análisis del nivel de impacto y mercadotecnia de las organizaciones inscritas a la Red de Atención y Prevención de la Violencia", en Dimensiones del desarrollo social y humano: estudios selectos (Guanajuato: Observatorio Académico de Desarrollo Social y Humano en Guanajuato, 2017). teodorahurtado@yahoo.es. 


\section{Introducción}

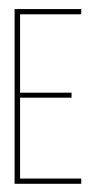

l término coloquialmente usado para nombrar la compraventa de servicios sexuales ha sido el de prostitución. En la actualidad, este término coexiste junto con otros vocablos acuñados desde la academia y por algunos movimientos sociales de mujeres; es así que conceptos como trabajo sexual, servicios sexuales, sexo comercial y sexo de paga hacen su incursión en los discursos de académicos, políticos y de colectivos en defensa de los derechos humanos de las mujeres que ejercen la prostitución o como estrategia para dignificar y modificar, de manera sustancial, los modos en que social y políticamente se percibe esta actividad. En sus estudios, autoras como Kamala Kempadoo (1998, 2005), Laura Agustín (2000, 2005), Dolores Juliano (2002, 2004), Saskia Sassen (2003), Adriana Piscitelli (2005, 2007), Lin Lean Lim (2010), Teodora Hurtado (2015), entre otras, plantean la pertinencia del uso y significado diferenciado de los términos trabajo y prostitución. Por lo anterior, apelan al empleo de conceptos como trabajo sexual (sex work) y sexoservicio. Estos términos conviven cotidianamente, pero mientras que la noción de prostitución hace referencia a una ocupación estigmatizada, marginal y precaria, considerada como violencia de género, trata o esclavitud, con la noción de trabajo esta actividad es descrita como una forma alternativa de ganarse la vida o de autoempleo.

El carácter equívoco y desacreditado del término prostitución se sustenta en el sesgo de género y en la carga moral peyorativa que recae casi exclusivamente en las mujeres trabajadoras, al reducir la participación masculina al consumo, y al excluir e invisibilizar la intervención de los hombres en otras etapas de la cadena productiva: producción, mercantilización y lucro. Entre tanto, la categoría de trabajo ofrece una visión de conjunto y reconoce las relaciones de producción y explotación entre prestadoras de servicios, usuarios y empresarios, que subyacen al ejercicio del trabajo sexual. No obstante, ambas conceptualizaciones se refieren, en particular, a la comercialización y prestación de servicios sexuales, emocionales y afectivos, aunque en este mercado también se distribuyen productos de otra índole.

Al hacer referencia a los productos y servicios de consumo y denominarlos servicios sexo-afectivos, aludo al conjunto de bienes inmateriales y simbólicos demandados en el mercado del sexo. Estos bienes son inmateriales y corpóreos a la vez, porque no se pueden almacenar pero se producen, distribuyen, circulan y consumen a través del cuerpo de la trabajadora y del cliente. Además, en el proceso de comercialización, los consumidores, en vez de sexo, pueden comprar otros 
servicios como tiempo, compañía, cuidado, atención y afecto, dependiendo de la fantasía erótica, afectiva o emocional que deseen satisfacer. El componente simbólico también está ligado al carácter intersubjetivo e interrelacional de dicha transacción, dado que a través de ella lo que el cliente adquiere temporalmente es poder, sumisión, deseo o fantasía, y lo que ofrece la trabajadora es la posibilidad de hacer realidad, de manera parcial o total, las demandas a cambio de un pago.

La intersubjetividad, por su parte, se vincula a la construcción y al imaginario del Otro, en tanto mercancía o sujeto cosificado y transformado en objeto de deseo, y a la construcción e imaginario sobre sí mismo como beneficiario o no de dicha transacción. En el caso del cliente, se trata de la búsqueda de satisfacción. En cuanto a la trabajadora, es un proceso más complejo que implica el desdoblamiento de su cuerpo y su persona ${ }^{1}$. Es decir, desde su propia subjetividad ella trata de separar a la persona del objeto cuerpo; dicha separación le permite convertirse a sí misma en la mercancía sexo en el momento de ejercer su trabajo. Aunque dicho desdoblamiento sea solo una pretensión.

No obstante, como lo señala Lim (2010) y como lo discutiré en este artículo, el mercado del sexo no es un entorno homogéneo, al contrario, está compuesto por distintos segmentos que incluyen una gran diversidad de actores sociales. Cuando quienes ejercen este trabajo son personas adultas, el abanico de situaciones es amplio. Algunas han elegido libremente esta actividad como expresión de liberación sexual o como decisión económica racional, otras son empujadas a ella por la miseria y la falta de otras oportunidades, mientras que hay quienes son objeto de presiones ejercidas por terceros, mediante violencia física o psicológica (Hurtado 2011, 2013a, 2015; Lamas 2014). Al igual que las formas de reclutamiento, las condiciones laborales también varían ampliamente, por tanto, en este mercado de trabajo son decisivos los tipos de inserción laboral.

Este estudio, de corte sociológico, examina la producción social del mercado global del sexo y las intersecciones entre las formas de opresión y privilegio por condición de género, etnia/raza, clase y nacionalidad que afectan a los agentes sociales que lo integran, sea que se desenvuelvan en calidad de fuerza de trabajo o como consumidores y empresarios. A diferencia de la antropología,

Al hablar de desdoblamiento hago referencia al distanciamiento del ambiente que procura construir la trabajadora sexual entre ella (o su cuerpo) y la prestación de servicios: la compraventa de sexo-afecto. Desde esta disyunción, ella procura desligar la experiencia física y emocional que implica su trabajo de la experiencia física y emocional de su mundo de vida. Tal distanciamiento de la realidad se caracteriza por la presencia de una variedad de construcciones mentales como mecanismo de adaptación o de defensa, a partir de las cuales intenta dominar, minimizar o tolerar el estrés y otras sensaciones corporales y mentales como el fastidio, el conflicto, la ansiedad, las náuseas e incluso el placer que puede sentir. 
donde existe una producción considerable y empíricamente fuerte sobre el trabajo sexual en diversos contextos, en la sociología dicha actividad había sido concebida, hasta épocas recientes, como una problemática ajena a los estudios laborales y limitada a unas cuantas investigaciones de la sociología del trabajo ${ }^{2}$. Pero, debido a su emergencia como forma alternativa de trabajo y de explotación laboral, y por la relevancia que los estudios feministas le otorgan a este tipo de labores emocionales y de servicio que se encuentran feminizadas y sexualizadas, la producción teórica y las investigaciones sobre el tema han adquirido una importancia creciente.

Este artículo es una contribución al estudio del trabajo sexual y los trabajos asociados al cuidado y a las emociones, que actualmente están en auge en las discusiones sociológicas sobre mujeres inmigrantes y habitantes de América Latina y el Caribe, que se desenvuelven en este mercado a escalas local e internacional. Su relevancia radica en que me aproximo al tema desde la teoría económica clásica y neoclásica para entender y exponer un fenómeno social hasta ahora poco investigado, a partir de datos empíricos, de la reflexión teórica y de una producción analítica conceptual, que dan cuenta del trabajo sexual como actividad productiva y reproductiva y como parte de la relación capital/trabajo, que tiene al cuerpo como escenario para la producción, distribución, circulación y consumo de la mercancía sexo-afecto. El trabajo se sustenta en diversas investigaciones realizadas entre los años 2009 y 2016, que implicaron revisión de literatura sobre el tema desde las teorías feministas, los estudios en torno al cuerpo y la sexualidad, así como de la teoría sociológica del trabajo.

El sujeto/objeto de estudio son las mujeres inmigrantes, más específicamente, mujeres afrocolombianas que participan en la industria del sexo en España. También hice observaciones de campo y entrevistas profundas en Co-

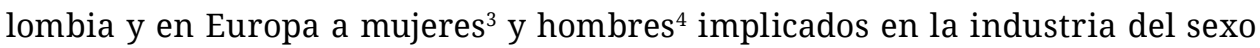

Los estudios vinculados a la sexualidad, y en particular a las prácticas sexo-afectivas - pagadas o no-, son recientes en las ciencias sociales y humanas. Las aproximaciones a este campo provienen fundamentalmente de la psicología, la sociología y la antropología, desde las décadas de los sesenta y ochenta, como resultado de la revolución sexual y la irrupción del VIH/sida respectivamente, con predominio de los enfoques higienistas, de salud sexual y reproductiva o de salud pública (Guasch 1993).

3 En el caso de las mujeres, entrevisté en Colombia y España a doce afrocolombianas, residentes $\mathrm{u}$ originarias de la ciudad de Cali y el municipio de Buenaventura; quince colombianas mestizas, en España; veinte mujeres dominicanas afrodescendientes y mestizas, cuatro españolas, dos portuguesas, una argentina y dos uruguayas. También entrevisté a tres inmigrantes africanas y tres de Europa, todas con experiencia de trabajo en el mercado del sexo y de los cuidados en España e Italia. último fue trabajador y parte de una red de inmigración para la industria del sexo. Todos 
como trabajadores, clientes, empresarios e integrantes de redes de migración y trabajo. De igual modo, incorporo los discursos de otros sujetos de las comunidades de origen (Colombia) y destino (España): miembros de ONG como Médicos del Mundo, Fundación Caritas y Colectivo Obrero (CC-OO, organización sindical de origen español), entre otras fuentes de información ${ }^{5}$.

En la primera parte del artículo abordo la reciente ${ }^{6}$ construcción social del mercado del sexo-afecto como escenario para la producción, consumo y distribución del sexo en tanto mercancía, y cómo, en un mercado globalizado, las mujeres inmigrantes con características diversas se convierten en las principales proveedoras de este servicio, según las jerarquías establecidas por su condición de sexo-género, clase, etnia/raza, nacionalidad, orientación y prácticas sexuales. En la segunda parte, presento algunas conclusiones en torno a los aspectos más relevantes del análisis del mercado del sexo como una construcción social, en la que intervienen hombres y mujeres (trabajadoras, clientes y empresarios) individual y colectivamente para hacer del sexo-afecto una mercancía globalizada.

\section{Hacia una delimitación del mercado y de la industrialización de los servicios sexo-afectivos}

Luego de establecer la diferencia entre la noción de prostitución y la de trabajo sexual, es importante señalar que en este escrito empleo estos y otros términos

ellos contaban con experiencia de vida en España e Italia, aunque las entrevistas se hicieron en Colombia entre el 2009 y el 2010. Otros cuatro entrevistados eran de origen español: tres eran o habían sido clientes consumidores de servicios sexo-afectivos y otro era parte de un grupo de empresarios del sexo en España. La estrategia de acercamiento a estas personas fue el método de bola de nieve.

$5 \quad$ El trabajo de campo lo llevé a cabo en el marco de mi investigación doctoral en Sociología de la UAM-Iz, bajo la orientación de Sara María Lara Flores.

6 Por reciente o moderna producción social del sexo-afecto como mercancía me refiero al hecho de que el proceso de globalización, el desarrollo de Internet, el abaratamiento del transporte aéreo, la reducción de las restricciones en la política migratoria, el turismo sexual y la complejidad de las redes transnacionales de migración han fomentado el desplazamiento de los trabajadores del sexo hacia los países de consumo, cuando antes el mercado estaba integrado básicamente por fuerza de trabajo local. Asimismo, han permitido el encuentro entre ofertantes y demandantes de sexo-afecto con diversas características sociodemográficas y económicas, la diversificación de los bienes y servicios y de las estrategias de consumo (Hurtado 2011, 2013a, 2013b). 
indistintamente (sexo-servicio, sexo de paga, sexo comercial, entre otros) con el propósito de nombrar el ejercicio de la prestación de servicios sexuales a cambio de dinero en un contexto de mercado. Esta conceptualización toma en cuenta el hecho de que esta no es una actividad en solitario, al contrario. Primero, hace parte de un mercado que engloba la comercialización y el consumo de sexo en múltiples formas, entre las cuales se encuentran la pornografía, las líneas telefónicas, el sexo virtual, el cine erótico, los cuartos oscuros, los shows sexuales (table dance, striptease, go-go girls, bailarinas de topless), entre otros. Espectáculos y escenarios en los que el atractivo sexual y erótico se convierte en mercancía y se emplea tanto para captar como para proveer a los clientes (Hurtado 2011).

Segundo, la mercantilización del sexo como bien de consumo y su vínculo con otros mercados (de los trabajos de cuidado, la hotelería y el turismo, por ejemplo) han facilitado la prestación de servicios sexo-afectivos a escala global (Agustín 2005; Hurtado 2013a). Tercero, es parte de una empresa que responde a estructuras económicas organizadas. La industria del sexo lo es en tanto obedece a un sinnúmero de intereses individuales y colectivos para producir ingresos y obtener beneficios de esta actividad (Lim 2010). En este negocio participan directamente ofertantes y demandantes e, indirectamente, otros actores sociales y otras actividades económicas legales (servicios estéticos, taxis, hoteles de paso, trabajos de cuidado doméstico) e ilegales (trata de personas, tráfico de estupefacientes y turismo sexual). Especialistas como Sassen (2003) y más recientemente Poyatos (2008) subrayan la importancia que tiene el comercio del sexo para ciertas sociedades; algunos países del Sudeste Asiático, por ejemplo, patrocinan el desarrollo del mercado sexual como parte de su producción económica, en tanto que Holanda y Alemania han legalizado la prostitución como una ocupación y reconocen los derechos laborales de las personas que ejercen tal actividad ${ }^{7}$.

El mercado de distribución y consumo de experiencias sexuales ${ }^{8}$ se caracteriza también por la variedad de espacios, formas y procedimientos para

7 Tarrius (2010) describe cómo las redes de traficantes de mujeres para el trabajo sexual y el comercio transnacional entre países del Mediterráneo se encuentran asociadas con autoridades locales en Granada y Málaga, en el caso español. Con la complicidad de las policías locales y marroquíes, estas autoridades facilitan el tráfico de jóvenes mujeres marroquíes para la prostitución en la Costa del Sol y las grandes ciudades del sur español, así como los trueques entre mercancías y hachís, mientras que los holandeses controlan la distribución de cocaína en los clubes nocturnos y a las trabajadoras sexuales. Estas actividades se han institucionalizado dentro del espacio Schengen (150).

8 Las investigaciones de Alain Tarrius (2000, 2002, 2010) en el Mediterráneo constatan que la implantación de la "mercancía-mujeres" permite la legalización de capitales de procedencia ilícita y el blanqueamiento de la "mercancía-droga". Una parte importante de la distribución de esas mercancías supone la circulación de los actores involucrados en esos mercados y genera flujos transnacionales de larga distancia. Tarrius (2010) plantea que la movilidad de 
la compraventa de sexo (Agustín 2000; Hurtado 2011; Lim 2010; Piscitelli 2005). En cuanto a los espacios, se ha creado una infinidad de escenarios reales o virtuales entre los que se puede mencionar burdeles, casas de citas, clubes, bares, discotecas, cabarets, cabinas privadas, salones de cóctel, cuartos oscuros, casas de masajes, saunas, restaurantes eróticos, agencias matrimoniales, salas de cine, tiendas de video, portales de Internet, hoteles, pensiones, pisos, casas de lujo y, por supuesto, la calle.

Sin duda, como lo plantea Lim (2010), en esto han tenido una importante contribución las evoluciones tecnológicas como Internet, la expansión del turismo, las agencias de viajes y los medios masivos que se encargan de publicitar los diversos servicios sexuales que se ofrecen y que responden a una demanda cada vez más sofisticada. También cabe mencionar las líneas telefónicas calientes, el sexo virtual, los sex shops, los masajes, los servicios de acompañantes, las películas eróticas, las revistas pornográficas y los servicios de dominación o sumisión, entre otros. Estos servicios se ofertan mediante estrategias como los anuncios clasificados en radio, prensa y televisión, la impresión de tarjetas de presentación, la realización de páginas web y el establecimiento de teléfonos de contacto. Finalmente, se encuentra la propia diversificación de la fuerza laboral dedicada a ofrecer sexo, integrada por mujeres y hombres, niños y niñas, adultos y jóvenes, heterosexuales, homosexuales, bisexuales y transgéneros, principalmente.

En las naciones posindustrializadas, a partir de estos mercados e industrias se ha fomentado la existencia de trabajos precarios, marginales, estigmatizados, feminizados y racializados, hermanados con aquellos de prestación de servicios sexo-afectivos, cuidado de personas y limpieza, ocupados principalmente por mujeres migrantes que, a causa de las condiciones materiales de existencia y de otras motivaciones en sus países de origen, migran y se insertan en estos nichos de empleo (Hurtado 2011). La situación anterior no se explica solamente por las diferencias de género o clase, ni por la división social del trabajo. Los procesos de construcción social de los mercados de trabajo y de las ocupaciones ${ }^{9}$ conectadas con el sexo involucran relaciones de poder, dominación y de

esas mercancías se organiza con todo cuidado en función de su rentabilidad. Así, detecta al menos cuatro tipo de redes de transmigrantes vinculadas a la prostitución, cada una bien diferenciada por sus organizaciones, pero operando en el mismo territorio de circulación: 1) mujeres para el trabajo sexual, en situación legal o tolerada, o en situación ilegal, según el país; 2) parentela de esas mujeres, sobre todo femenina, legalmente empleada; 3) hombres que trabajan en el comercio "de pobre a pobre" de productos electrónicos, y 4) la menos visible, traficantes de psicotrópicos. Todos ellos conforman un universo de transgresiones, travesías y circulaciones (134). 
producción, construidas socialmente y sustentadas en asimetrías en las que la etnia/raza, el lugar de origen, la condición migratoria, la orientación y las prácticas sexuales también inciden en la participación de agentes sociales cuyas identidades se hacen cada vez más visibles en la moderna producción social del sexo de paga (Hurtado 2011, 2013b, 2014).

\section{Segmentación socioocupacional de las mujeres en el mercado de los trabajos sexuales}

En este apartado describo las asimetrías en las relaciones sociales de producción y de poder que se exhiben en el trabajo sexual, a causa de las interseccionalidades que se desprenden de las desigualdades de sexo/género, etnia/raza, clase, condición migratoria y lugar de trabajo, entre otras situaciones cotidianas a las que se ven expuestas las mujeres (también los hombres y las personas trans) que se dedican a esta actividad como fuerza de trabajo.

La globalización económica, el desarrollo tecnológico y las oportunidades de estar interconectados a escala planetaria han contribuido al rápido aumento de la infraestructura institucional y económica para la conformación de los circuitos migratorios transfronterizos y la mundialización de los mercados de trabajo (Castles y Miller 2004). Estos circuitos y mercados, como la industria del sexo y varios tipos de trabajo de cuidado, son enormemente diversos pero comparten algunas características en común: se han feminizado, son rentables y generan beneficios a costa de la explotación laboral y sexual de las mujeres. Arango (2010, 86-90) añade que estas ocupaciones integran las nuevas formas de división internacional del trabajo feminizado; además, favorecen el incremento de las desigualdades de género, las asimetrías basadas en la nacionalidad y la estigmatización de las identidades étnicas/raciales de las mujeres del llamado Tercer Mundo. Según Castells (2001, 182-200), las razones para contratarlas se encuentran en los aspectos objetivos y subjetivos de su condición de fuerza laboral: bajo costo de inversión, precio barato de la mano de obra y alta capacidad de relacionarse socialmente, aspectos cada vez más necesarios en una economía

interpretamos como parte de este proceso las experiencias de empleo (oferta y demanda de fuerza de trabajo) que resultan de la división social y sexual del trabajo (De la Garza 2000). 
de la información y de servicios, donde la administración de las cosas queda en segundo plano frente a la gestión de la gente. La nueva economía requiere cada vez más de las “destrezas femeninas” que estaban confinadas al ámbito privado, pero su flexibilidad como trabajadoras es lo que les permite integrarse, en mayor proporción, en los empleos precarios temporales o de tiempo parcial.

En el caso de las mujeres del Tercer Mundo, existen otras razones para ser contratadas o reclutadas en este tipo de ocupaciones. En los países "del norte” ellas hacen las tareas "sucias”, "subvaloradas” e "indignas”, es decir, las labores de cuidado, de trabajo doméstico y de servicios sexuales que muchas de las mujeres nativas no están interesadas en realizar, justamente por el carácter precario de las condiciones de trabajo de esos mercados y porque son valorados como degradantes (Arango 2010; Hurtado 2011). No obstante, algunos estudios (Hurtado 2011; López 2010) y propuestas analíticas (Agustín 2005; Benería 2003; Parella 2005; Piscitelli 2005; Sassen 2007) enfatizan que los procesos de globalización entre el norte rico y el sur pobre también han generado un vínculo muy cercano entre trabajos de servicios personales, como la prostitución, el cuidado de personas y el trabajo doméstico.

Soares (2012) plantea que la mayor parte del trabajo de cuidar - así como de atender a un cliente en el trabajo sexual- hace parte del "proletariado emocional”, cuyas posibilidades de decisión y prestigio social son bajas (52). Por ello, las mujeres son más propensas a las humillaciones y están más expuestas a tratos violentos, y la intersección de género, raza, clase social, edad, entre otras, agudiza esta condición de vulnerabilidad. Así, ciertas ocupaciones surgen y se consolidan bajo el estigma de labores ejercidas por personas explotables (Wade 1997, 232). Hirata y Guimarães $(2012,3)$ plantean que la profesionalización de los trabajos de cuidado cuestiona el carácter "natural” o "innato" que ha querido dárseles no solo en el ámbito mercantil, sino también en el espacio doméstico.

Soares (2012, 62, citando a Heller) señala que la división sexual de las emociones es construida socialmente y conlleva una jerarquización de las emociones expresadas por las mujeres, consideradas a veces como inferiores, otras como superiores, pero rara vez como iguales a las manifestadas por los hombres. En el mercado del sexo, esto último queda muy claro en la medida en que una serie de juicios de valor o de estereotipos vinculados a los supuestos modos de ser y del hacer de las mujeres racializadas (ser cariñosas, pacientes, dóciles o hipersexuales) son sobrevalorados (Hurtado 2011). La noción de etnosexualidades, desarrollada por Piscitelli (2005), nos sirve para nombrar este fenómeno de imputación de conductas y habilidades a individuos y colectivos, con base en los rasgos identitarios y de género más evidentes; en segunda instancia, para explicar que en 
estos mercados las múltiples sexualidades y etnicidades se convierten en patrones de consumo de los que se beneficia, y a la vez son favorecidos por la reproducción del capital. Por consiguiente, el resultado de esta etnosexualidad es la emergencia de nuevos escenarios de racialización, feminización y sexualización de las mujeres, en general, y de las mujeres negras (y de los hombres negros), en particular. De esta manera, en el mercado del sexo los países pobres de América Latina, Asia, África y Europa del Este adquieren relevancia como áreas geográficas desde donde se exportan, no solo mujeres, sino estereotipos sexuales y raciales hacia la Europa, la América y el Asia desarrolladas. Esto coincide con el recrudecimiento de las condiciones de vida de la población de dichas regiones, así como con el auge del turismo (Ariza 2004; Hurtado 2011; Kempadoo 1998; Lim 2010; Piscitelli 2005, 2007).

$\mathrm{Al}$ analizar estos factores en conjunto durante el trabajo de campo en Colombia (en el 2009), España (entre los años 2009 y 2010) y México (entre el 2011 y el 2013), para entender cómo se sitúan las mujeres afrocolombianas y otros colectivos de mujeres racialmente diversas de Colombia, Brasil, República Dominicana, Argentina, Venezuela, Europa del Este ${ }^{10}$ y, en menor medida, de países africanos ${ }^{11}$, inscritas en los diferentes puestos de trabajo sexual (en la calle, pisos de contacto, establecimientos y hoteles en España y otros países de Europa), observé que el mercado del sexo comercial es un ámbito polarizado, estratificado y segmentado. Este mercado está integrado fundamentalmente por tres esferas productivas: la prostitución de lujo o de alto standing dirigida a los sectores de élite, la prostitución enfocada en las clases medias trabajadoras y la prostitución para los sectores populares o empobrecidos, que se ejerce en espacios públicos, austeros y precarios (principalmente en la calle y en los parques públicos). Esto significa que la posibilidad de ocuparse o no en uno de los puestos de trabajo que ofrecen los diferentes segmentos que componen la industria del sexo depende de cómo se incorporan las mujeres a este mercado de trabajo y cómo las distintas asimetrías ponen en marcha una cadena de opresiones o de ciertos privilegios.

Hay una cultura de la migración que incluye argentinos, venezolanos y uruguayos, aquí esos son muy bien considerados. Después estamos con las suramericanas blancas, después con las suramericanas de color, después con las... ¡no...! A las rusas quizás las coloco con las suramericanas blancas, después las suramericanas de color y después las africanas. ¡Claro! En lo último. Ellas tienen la posibilidad de todos los insultos posibles, no solo eres puta, es que además eres negra, además

\footnotetext{
10 Mujeres oriundas de Rumania, Hungría, Lituania, Ucrania y Rusia.

11 Como Níger, Nigeria, Marruecos y Camerún.
} 
eres mujer y es que además trabajas en la noche, bueno, tienen ya todo, todos los estigmas. Entonces cómo vas a salir de ahí [del trabajo sexual de calle], claro, eso resulta muy complicado. (Mujer española, trabaja en el Centro de Información a Trabajadores Extranjeros del Colectivo Obrero, entrevistada por Hurtado en el 2010)

Estos sistemas de relaciones sociales de opresiones y privilegios ${ }^{12}$ basados en asimetrías identitarias hacen que algunas mujeres, cuyos rasgos las sitúan en el extremo de los privilegios (blancas, rubias, de origen europeo, delgadas, universitarias, etc.), tengan más posibilidades de ocupar los puestos de trabajos sexuales mejor remunerados y con mejores condiciones laborales, que las que se ubican en el margen de la opresión (mujeres negras, de origen africano, pobres $\mathrm{y}$ de bajos niveles educativos). No obstante, en esta industria las mujeres, tanto las que disfrutan de los privilegios como las que no, se sitúan en una condición de desigualdad de género, pues son quienes principalmente ofrecen servicios sexuales y afectivos a los hombres que los demandan. La prostitución agudiza así el problema de la dominación de género, pues son sobre todo los hombres ${ }^{13}$ quienes demandan que los cuerpos de las mujeres subalternizadas sean vendidos como mercancía, asegurando el acceso a sus cuerpos, las relaciones de poder y el orden social heteropatriarcal.

Patricia Hill Collins (2000) retoma el concepto de interseccionalidad, acuñado por Kimberlé Williams Crenshaw en 1989, para explicar desde la teoría de la interseccionalidad las identidades sociales como el género, la etnia, la raza, la clase, la discapacidad, la orientación sexual, la edad, la nacionalidad y otros ejes de identidad y los sistemas de relaciones sociales de poder a los que se integran: opresión/privilegios, dominación/sumisión, reconocimiento/ discriminación. La teoría manifiesta cómo las categorías identitarias biológicas, sociales y culturales, a las cuales ella define como vectores de presión o de privilegios, interactúan en múltiples y simultáneos sistemas de relaciones sociales, favoreciendo a las personas cuyos vectores o rasgos identitarios se sitúan en el espacio de los privilegios, y son más precarios para los que no, para comprender de forma completa la propia identidad, las desigualdades, la discriminación y las relaciones sociales de poder y dominación.

13 Los datos empíricos y documentales que recopilé, al igual que los estudios que cito, corroboran que, pese a su anonimato, los clientes o usuarios de servicios sexuales son, casi siempre, hombres, aunque mujeres y personas LGTB también recurren ocasionalmente a este mercado. Este actor "anónimo y huidizo" del cual se sabe muy poco (Corso 2004; López 2010; López y Baringo 2007) no cuenta con un perfil único y definido; por tanto, cualquier hombre puede ser un consumidor potencial de sexo comercial. Meneses $(2003,2007)$ señala la existencia de clientes -o prostituidores, como los denomina - que se distinguen por ser objetualizadores o personalizadores. Los primeros construyen una relación meramente instrumental con la trabajadora, mientras que los segundos se inclinan por establecer ciertos vínculos con quien les presta dichos servicios, que pueden llegar más allá de lo estrictamente comercial. Un tercer tipo de usuarios, a los que Meneses califica de clientes o prostituidores agresores, son los que se valen de la coacción, la intimidación y la violencia durante la prestación de servicios. Otras definiciones o tipologías son: buenos o malos, normales o problemáticos o pesados. López y Baringo (2007) señalan que los hombres españoles que consumen sexo de paga no tienen un aspecto definido; se trata de una población muy heterogénea en edad, ocupación, nivel socioeconómico y estado civil. 
En el mercado del sexo, al igual que para el conjunto de los trabajos de proximidad, afectivos y de cuidado que hoy forman parte de la división internacional de los trabajos femeninos, las características físicas, como el fenotipo o la raza, los lugares de origen y los patrones culturales o de conducta que se les atribuyen (ser cálidas o frías, amables o sumisas, fuertes o débiles) se conciben como bienes inmateriales y valores simbólicos agregados a su condición de mano de obra no calificada, sin importar su nivel de instrucción académica o profesional. A la vez, se las construye como mano de obra y como cuerpos cualificados para el ejercicio de estos oficios en los que, en apariencia, no se requieren conocimientos. En este sistema capitalista y de relaciones patriarcales el solo hecho de ser mujeres las pone en una situación desigual y de subordinación al capital/ trabajo y a los hombres. Tales estigmas permean no solo a los clientes, sino a las propias trabajadoras, que asumen como real la naturalización de dichas cualidades, como se percibe en este relato:

Para ellos [los españoles] el color de piel es algo atractivo, les gusta mucho una mujer extranjera, les gusta mucho la raza negra, les encanta, les fascina. Ven una morena y les gusta, y si la morena es guapa, más todavía. Casi la mayoría de las paisanas que han emigrado por $x$ o $y$ motivo al extranjero siempre, siempre, terminan con un blanco; porque ese color a ellos les atrae, les fascina, les llama la atención.

Sí, hay preferencias dependiendo del color de piel. A ellos les gusta mucho una mujer latina, puede que de los países del Este de Europa haya mujeres guapas... guapísimas, altas, de ojos verdes, azules, claros; pero a ellos les gusta mucho la mujer latina, así sea blanca, rubia, negra, paisa, pero latina. Se debe a la cultura, por ejemplo, las colombianas, las mujeres somos muy especiales, somos muy amables, nos ganamos el cariño, damos cariño y le sacamos una sonrisa al más bravo... A un león le sacamos una sonrisa... de verdad. (Mujer afrocolombiana de Buenaventura, 42 años de edad, migrante en Italia y luego en España, ejerció como trabajadora sexual en la calle, entrevistada por Hurtado en el 2010)

Los patrones de exclusión social pueden intersectarse e interactuar con los prejuicios sexuales y los estigmas raciales. Por ejemplo, las mujeres afrodescendientes y las latinas son imaginadas como personas estéticamente guapas, con cuerpos esculturales y posturas seductoras, que hacen suponer el ejercicio de una hipersexualidad desbordada, libidinal y desregulada. Estudios de la Cepal (2003a, 2003b) demuestran que la interfaz entre género, condición étnica/racial y sexualidad en contextos transnacionales no es reciente. Desde la época colonial, las mujeres, particularmente las africanas e indígenas, eran motivo de tráfico con un triple propósito: someterlas a la condición de mano de obra gratuita, de 
reproductoras de nuevos esclavos y para servir como objeto sexual. Propósitos que de alguna manera hoy en día se hacen presentes en el mercado sexual y matrimonial ${ }^{14}$. Asimismo, las formas actuales de tráfico de personas no son muy diferentes, ni escapan a esta lógica esclavista, colonialista y machista.

Al analizar estos factores y entender cómo se sitúan las mujeres colombianas y otros colectivos de mujeres en los diferentes puestos de trabajo, en España se observa ${ }^{15}$ que estos sistemas de relaciones sociales hacen que algunas colombianas, cuyos atributos se sitúan en el extremo de los privilegios, ocupen puestos mejor remunerados y con mejores condiciones laborales, en tanto que otras, con las mismas características pero con identidades subvaloradas, se ubican en el margen de la opresión y experimenten condiciones laborales precarias. El trabajo sexual de alto standing, de lujo o de escorts se constituye en el segmento del mercado más imperceptible y discreto, al realizarse en establecimientos reservados, elegantes y costosos, a los cuales solo se llega con cita previa. Los clientes o usuarios tienen perfiles profesionales diversos, poder político y socioeconómico o el capital financiero y cultural necesario para demandar "servicios sexuales profesionales” en este nivel.

$\mathrm{Al}$ estar menos restringidas por las condiciones laborales extremas, las trabajadoras de este sector cuentan con ingresos elevados, estatus laboral, posibilidad de estabilidad ocupacional y de autonomía en la toma de decisiones. Generalmente, son contratadas por las agencias como trabajadoras exclusivas de uno o pocos clientes, de forma temporal, ocasional, durante periodos cortos o de unos cuantos años (de dos a cinco en promedio). Se trata de mujeres muy jóvenes o menores de treinta años, con un nivel educativo y cultural alto, con perfiles de modelos de pasarela, actrices y reinas de belleza (blancas, rubias, de ojos claros, de origen europeo, delgadas y altas), que reflejan una lógica de segregación socioeconómica, sociolaboral, étnica/racial, por su lugar de origen y por los patrones dominantes de belleza. Según Cantarero (2007) y Trujillo (2009), en estos espacios escasamente se aceptaban mujeres de tez oscura o mayores de treinta años. No obstante, para complacer las fantasías sexuales, eróticas amorosas o la sofisticación del gusto de los clientes, y ampliar y diversificar la variedad

En el estudio realizado en España encontré que las redes transnacionales de tráfico analizadas también recurrían a estrategias de captación y reclutamiento forzado de personas. Tales estrategias empresariales les permitían establecer criterios de selección de las inmigrantes en función de sus disímiles posibilidades de inserción laboral, de explotación económica o como mercancía: mujeres para el trabajo sexual, mujeres para el cuidado de personas, mujeres para el trabajo doméstico, mujeres para la industria matrimonial (Hurtado 2011, 147). 
de la fuerza laboral, los empresarios permitieron la entrada de un número moderado de trabajadoras de origen latino, particularmente argentinas, venezolanas, puertorriqueñas, dominicanas, brasileras y colombianas, entre las que había algunas negras. Varias de las afrocolombianas tenían altos niveles educativos y provenían de sectores sociales medios y altos de Cali y Buenaventura, y vieron en la prestación de servicios sexuales una estrategia para impulsar y mantener su estatus socioeconómico o para consolidar su proceso de movilidad social ascendente en el país de origen. Eran universitarias y modelos que trabajaban durante periodos cortos en Europa, con contratos laborales que no superaban unos cuantos años y con ciclos de descanso en los que volvían a Colombia. Al concluir su estancia de trabajo en España y el resto de Europa, a veces retornaban para radicarse definitivamente en el país, con el capital económico suficiente para promover y proyectar su futuro profesional o empresarial e impulsar los procesos de movilización de otras mujeres.

El siguiente nivel de este esquema organizativo, en el que podemos encontrar un mayor número de mujeres afrodescendientes, son las casas de citas o clubes de alterne, los hoteles plaza, los pubs, los clubes nocturnos, entre otros lugares de entretenimiento concebidos fundamentalmente para el ocio y la prestación de servicios sexuales. La distribución de las mujeres que trabajan en estos lugares es más diversa e incluyente: delgadas o robustas, altas o bajas, rubias o morenas, con distintas tonalidades de piel, jóvenes o "maduritas" —mayores de treinta años - e incluso menores de edad. Esta amplia gama de lugares, con estándares socioeconómicos y condiciones laborales diversas, también abarca los apartamentos de contacto. Pero mientras que los clubes se asocian con organizaciones de tráfico y trata de personas, como escenarios de explotación sexual y laboral, o en los que sus dueños se lucran con el ejercicio de la prostitución de mujeres extranjeras, los apartamentos de contacto son lugares imperceptibles, espacios poco visibles donde laboran las mujeres que trabajan de manera autónoma o se han convertido en empresarias del sexo. Muchas de ellas concluyeron su tiempo de trabajo en el club, pagaron la deuda que implicó su traslado y están en condiciones de independizarse. Son mujeres que desarrollaron habilidades, aprendieron el oficio y quieren conformar su propia empresa, solas o en asocio con otras personas. En estos lugares son numerosas las mujeres negras latinas de República Dominicana, Colombia, Brasil, Cuba, Ecuador y Venezuela, al igual que las de origen africano. No obstante, las mujeres afrolatinas son menos vulneradas por las relaciones sociales asimétricas, gracias a que sus atributos étnicos/ raciales, estéticos y lugares de origen les otorgan una condición más favorable (Hurtado 2011). 
En el nivel más bajo de la jerarquía ocupacional del mercado se encuentran las diversas formas de ejercicio de la prostitución callejera: los parques, los polígonos industriales y las avenidas, donde las braceras del sexo se debaten entre la autodeterminación y la trata de personas, como formas de explotación laboral. Para Juliano (2004) no es casual que las mujeres españolas que provienen de los sectores más deprimidos, las drogodependientes y las inmigrantes de los países más empobrecidos del planeta sean quienes, en su mayoría, se sitúen en estos espacios de trabajo. Tampoco es fortuito que sean las inmigrantes africanas quienes permanezcan en este ámbito laboral durante mucho más tiempo ${ }^{16} \mathrm{y}$ las que experimenten escasas opciones de movilidad laboral, tanto en los niveles más altos de la industria del sexo como en otros mercados de trabajos precarios.

Lo indiscutible, y en lo que coinciden los distintos estudios, es que en los puestos de trabajo sexual de la calle se concentra una mayoría relativa de africanas, nigerianas y camerunesas, a las cuales se les unen las del este europeo: rumanas, croatas y ucranianas, originarias de países donde supuestamente predominan las mafias y las redes criminales que las trafican para "explotarlas" sexual, laboral y económicamente (López 2010). En la información empírica recopilada durante las observaciones de campo, descubrí que no siempre ocurre de este modo, y que tanto las mujeres africanas como las del este europeo son migrantes autónomas que recurren a las redes de inmigración fraternal, a las parentales y a las agencias para llevar a cabo el proyecto migratorio y laboral. Asimismo, mediante testimonios hallamos que algunas tenían conocimiento previo de que iban a trabajar en la industria del sexo.

Otros colectivos que también tienen presencia en estos espacios de trabajo son las mujeres inmigrantes de América Latina, las nativas españolas que superan los cincuenta años de edad o con problemas de drogadicción y personas homosexuales o transgénero (López 2010; Meneses 2007). Sin embargo, aunque el número de mujeres africanas subsaharianas sea menor en comparación con otros grupos de mujeres, la interseccionalidad de variables como la apariencia física, la clase, el lugar de origen, la condición migratoria, el estatus étnico/racial y socioocupacional contribuyen a que, en términos cualitativos, su presencia y

Estudios como el de Kempadoo (1998) y el de Piscitelli (2005 y 2007) proporcionan información sobre el itinerario migratorio de colectivos de mujeres racializadas, sexualizadas e inscritas en la industria del sexo. Piscitelli (2005) muestra que las imágenes iconográficas que se difunden de las mujeres africanas son las más estigmatizadas. Durante mi trabajo de recopilación de información en España, logré identificar que las africanas subsaharianas contraen deudas de viaje que superan los 45.000 euros y se demoran hasta 5 años en pagar tal suma; mientras que las de las mujeres latinas son significativamente menores a los 15.000 euros y las pagan en un periodo máximo de un año (hombre español representante de la ONG Médicos del Mundo, entrevista realizada por Hurtado en el 2010). 
participación sea más evidente y se legitime el perfil estereotipado de la "mujer africana prostituta de la calle" o el de la "chica negra prostituta ilegal pobre e inmigrante”, como lo describen otros autores (López 2010, 565).

\section{Una ocupación no tan atípica en espacios de trabajo típicos}

El trabajo sexual constituye un oficio que se aparta de las formas "típicas” del empleo asalariado (estable y de tiempo completo). Se trata de un trabajo inestable, de tiempo parcial, temporal y que en la mayor parte de las sociedades modernas no está protegido jurídica o socialmente. Estos hechos favorecen que se convierta en un empleo precario, regulado y permitido, en unos casos, pero prohibido, no registrado, ilegal, clandestino y fraudulento en otros (Neffa 2010, 47-50). En sociedades como la española, la mexicana y la colombiana, el ejercicio del trabajo sexual mantiene una condición legal sinuosa que se mueve entre la informalidad y la clandestinidad ${ }^{17}$. En España está permitido su ejercicio en lugares cerrados (clubes de alterne, apartamentos, etc.), pero la ley de extranjería agrega una variable que contempla la vigilancia de las mujeres extranjeras que ejercen la prostitución, supuestamente para evitar la trata de personas ${ }^{18}$. Esta variable es una fuente de vulnerabilidad en el ejercicio del trabajo sexual, pues si bien las mujeres extranjeras ejercen las mismas faenas que las nativas, están expuestas al control moral, social y laboral de terceros.

Aunque la prestación de servicios sexuales en la calle haga parte de los lugares comunes de la cultura urbana en las ciudades modernas y globales (Benería 2003; Sassen 2003, 2007), algunos sectores sociales se preocupan y molestan por los inconvenientes que conlleva el ejercicio de la prostitución en la vía pública, lo cual, desde su percepción, fomenta el deterioro de los barrios y las zonas

17 El Código Penal español, modificado en 1995, despenaliza la prostitución voluntaria y solo tipifica "delitos contra la libertad sexual" (proxenetismo, prostitución infantil o de discapacitados). Parte del principio de que la prostitución en sí misma no ha de ser ni reconocida ni prohibida por el Estado, por pertenecer a las relaciones privadas (Brufao 2008). En ese sentido, no se considera delito conceder el cuerpo propio con fines de lucro, con tal de que se salvaguarden las leyes emanadas de la tutela del orden público, como la prohibición de la seducción o de actos obscenos en lugar público, el atentado contra el pudor, la provocación al vicio, disposiciones que son interpretadas de modo cada vez más elástico.

Ley Orgánica 8 del 22 de diciembre del 2000, de reforma de la Ley Orgánica 4 del 2000, de derechos y libertades de los extranjeros en España y su integración social. http://isonomia10anys.uji.es/docs/spanish/investigacion/conferencia.pdf. 
comunales, afecta la imagen de la ciudad y pone en entredicho la moral pública. No obstante, en otros países europeos el ejercicio de la prostitución en las calles no es necesariamente estigmatizado, precario u oculto. Dado que el mercado del sexo es una actividad comercial altamente rentable, la prestación de servicios sexo-afectivos en la calle hace parte de la iconografía que distingue a ciertas ciudades, como Hamburgo y la calle de Ripperwand en el barrio Sankt Pauli, o París y los alrededores de Pigale, cerca del Moulin Rouge. Estos ejemplos demuestran cómo ciertos tipos de trabajo sexual de calle, estructurados, "bien expuestos” a la vista de los transeúntes y clientes, “bien explotados” desde el Estado o desde el sector privado ${ }^{19}$, atraen una amplia cantidad de público y generan dinero (Hurtado 2011; Oso y Ulloa 2001).

Sin embargo, quienes ejercen la prostitución en la vía pública son estigmatizadas. En España, esta se concibe como una actividad precaria realizada por extranjeras con características culturales y raciales subvaloradas, como las mujeres de tez oscura y, en particular, las de África subsahariana, quienes en el imaginario colectivo son la imagen más común de la prestación de servicios sexo-afectivos en el espacio público de la “prostitución” de calle.

Llama más la atención la latina, porque además somos negras. Aunque provenimos de África, porque el origen de la humanidad es en África, pero los negros latinos somos muy diferentes, en la forma de ser. Principalmente, porque las personas, las africanas, son muy agresivas, demasiado agresivas, muy violentas en el trato, en los gestos corporales, inspiran no sé, no sé, algo raro. (Mujer afrocolombiana de Buenaventura, 42 años de edad, migrante en Italia y España, ejerció como trabajadora sexual en la calle. Entrevistada por Hurtado en el 2011)

La legislación española acepta que en lugares como los clubes y los hoteles plaza se practique el alterne como actividad laboral (Poyatos i Mata 2008). Esto consiste en la captación de clientes hombres mediante el atractivo sexual, con el objetivo de que consuman la mayor cantidad posible de bebidas y otros productos como drogas. Aunque la ley no lo contemple explícitamente, el alterne es un trabajo sexual que puede ejercerse por cuenta propia o por cuenta de terceros, y se califica para todos los efectos jurídicos como una actividad autónoma o como

19 Aunque puede suscitar extrañeza e interpretaciones ambiguas, la noción de "bien explotado" se refiere al hecho de que al regular las condiciones de trabajo y de vida de las trabajadoras, mediante la formalización de la prestación de servicios sexuales como actividad laboral y legal, la seguridad social, el pago de impuestos, el fomento del turismo sexual -entre otras actividades económicas que pueden ser implementadas por el Estado o por el mercado-, la situación de vida de la fuerza de trabajo es menos precaria y la intervención de terceros es menor (redes de trata de personas, trabajo clandestino, explotación laboral y sexual, violencia de género). 
una relación laboral entre la mujer (u hombre) que ejerce el alterne y la persona (física o jurídica) beneficiaria de tal actividad (el empresario específico). Pero para las trabajadoras dicha relación laboral solo es jurídicamente comprobable si se presentan ante las autoridades correspondientes los contratos de trabajo o las notas de laboralidad ${ }^{20}$ requeridas para acreditar la existencia de un vínculo de trabajo. Las trabajadoras no tienen cómo comprobar dicho vínculo, debido a la verbalidad de los contratos y los acuerdos establecidos entre las partes. La prestación de servicios sexuales en el alterne no es reconocida por los empresarios. De hacerlo, sería tipificado como favorecimiento de la prestación de servicios sexuales a cambio de dinero y se consideraría delito del orden penal; además, si el empresario reconociera que existe una relación contractual, correría el riesgo de ser juzgado por proxenetismo.

La paradoja en el funcionamiento de estos espacios laborales es que las autoridades gubernamentales expiden permisos para la apertura de locales en los que, además del alterne, es de dominio público que las ganancias provienen básicamente del consumo de sexo-afecto comercial. Esta situación contribuye a la permanente ambigüedad jurídica, social y laboral del trabajo sexual, impide que quienes lo realizan sean reconocidos como sujetos de derechos laborales y favorece la precarización de sus condiciones de trabajo (Hurtado 2015; Lim 2004). Dado que la fuerza de trabajo ocupada en el mercado del sexo español es predominantemente inmigrante, esta situación se agrava porque no pueden reclamar el derecho de ciudadanía y están expuestas a ser controladas por la Ley de Extranjería, al no permitirse formalmente el ejercicio de trabajos sexuales como la prostitución. Las mujeres inmigrantes extranjeras o europeas y las nativas que ejercen como sexo-servidoras realizan su actividad en los apartamentos de contacto, las casas de lujo y los hoteles, por lo que gozan de mayor autonomía.

Al igual que Poyatos i Mata (2008, 12-16), constaté que la legislación española concerniente a la expedición de permisos para la apertura de locales en donde se ejercen la prostitución y el alterne es una normativa tímida, debido a que en muchos casos solo se requiere que los empresarios del sexo y los establecimientos cumplan con las condiciones urbanísticas y sanitarias exigidas por las administraciones gubernamentales encargadas. Estos hechos han favorecido la expansión de los espacios de trabajo sexual, lo cual se refleja en la geografía socioespacial de la industria del sexo en España, un mercado de consumo cotidiano que funciona social y económicamente de manera dinámica y fluida, al igual que otros mercados establecidos, como el turismo. 
En los últimos años, las nativas españolas han reducido de modo significativo su participación en estos mercados laborales y matrimoniales y han cedido - de manera voluntaria o forzada- estos espacios a las mujeres extranjeras (Cantarero 2007), no solo porque las europeas han experimentado movilidad laboral y socioeconómica ascendente y pueden dedicarse a actividades más valoradas y menos precarias, sino porque, al igual que otros sectores productivos, se trata de mercados de trabajos segmentados y estratificados. Por tanto, las mujeres nativas han ascendido a los niveles de élite en la prestación de servicios sexuales y ejercen, principalmente, como trabajadoras de lujo o en los apartamentos como trabajadoras autónomas; mientras que las mujeres migrantes, además de insertarse en los espacios de prestación de servicios sexo-afectivos que dejan las españolas, han abierto nuevos nichos laborales, diversificado la oferta e incrementado las posibilidades de acceder a experiencias sexuales y eróticas en el mercado del sexo de paga.

\section{Conclusiones}

Los procesos de organización social del sexo así como los discursos en torno a su comercialización se han transformado recientemente. Del mismo modo, existen variaciones sustanciales en la construcción social de la "prostituta" (o del prostituto) como sujeto laboral, ahora jurídicamente reconocida en algunos sectores y países como trabajadora (o trabajador) del sexo. La globalización y transnacionalización de la mano de obra y de los mercados han contribuido a esta realidad; asimismo, ha sido fundamental la participación de mujeres y hombres con sus múltiples identidades de género, etnia, raza, clase social, lugar de origen, orientación y prácticas sexuales, convertidos en las nuevas trabajadoras y los nuevos trabajadores del sexo-afecto.

Otro factor que incide en la moderna producción social del mercado del sexo es el hecho de que los aspectos subjetivos de orden emocional, moral, estético y cognitivo, entre otros, se hayan transformado en bienes simbólicos e inmateriales en el proceso de producción/consumo. Así, mientras algunos países europeos han reconocido la prostitución como trabajo, otros han favorecido el desarrollo de este mercado y lo han convertido en parte de una industria, legalmente reconocida o no, que genera altos ingresos y beneficios para las finanzas públicas y privadas. 
Desde una perspectiva jurídica y desde la sociología del trabajo, la precariedad del trabajo sexual se debe a que es un oficio que se aparta de las formas “típicas” del empleo asalariado, estable, de tiempo completo, con protección jurídica y social; al contrario, es una modalidad de empleo no registrado, ilegal, clandestino y fraudulento. De igual modo, reproduce las relaciones sociales de dominación de sexo-género y ocupación, y se aparta de la noción de trabajo “decente” por la carga moral que implica, sobre todo para las mujeres, el desarrollo de tareas "sucias", "subvaloradas” e "indignas", es decir, las labores de cuidado y de prestación de servicios sexuales. Estas condiciones favorecen que el trabajo sexual se mantenga en una condición legal sinuosa, entre la informalidad y la clandestinidad.

La forma en que se organiza el mercado del sexo y se estructura la pirámide socioocupacional hace que este oficio se perciba y se desarrolle como una ocupación etnizada, racializada, feminizada y dividida entre los espacios de trabajo para mujeres inmigrantes y aquellos para las mujeres nativas. También, el ejercicio de la prostitución se concibe como una actividad precaria ejercida por personas extranjeras con atributos culturales y raciales subvalorados, como sucede con las mujeres africanas subsaharianas, quienes se asocian con y representan la imagen pública de la prostitución de calle. Tal diferenciación hace que las mujeres inmigrantes, de acuerdo con sus características étnicas/raciales, lugar de origen, nivel educativo y prácticas sexuales, tengan más o menos opciones de ocuparse en los trabajos de nivel alto y medio debido al peso de la interseccionalidad de raza, etnia, clase y lugar de origen como vectores de opresión en unos casos y de privilegios en otros.

El efecto del color de la piel y del lugar de origen no se puede percibir como una categoría social secundaria, ni mucho menos análoga o subordinada a la nacionalidad. Al contrario, las identidades étnicas/raciales se interpretan como esencias de una naturaleza sexual, cultural y de clase que definen la ocupación entre sujetos sociales diversos, condición de la que difícilmente pueden escapar algunos colectivos. De acuerdo con las construcciones sociales a priori sobre el color de piel, la tez oscura o la piel "negra" han sido concebidas como referentes inmediatos de la ocupación y de la clase: mientras más oscuro el tono de la piel, más probabilidades de que una mujer sea considerada empleada doméstica (como ocurre en Colombia), se le llame "puta” en la calle y se le demanden servicios sexuales, como sucede en determinados contextos sociales en España, incluso entre mujeres inmigrantes que no han tenido experiencia como trabajadoras sexuales.

Dichos estigmas y estereotipos se viven como hechos cotidianos de los cuales una mujer negra difícilmente puede escapar y cuya identidad laboral está en 
duda permanente, por lo cual debe demostrar, de manera constante, que las intersecciones de género, clase, etnia/raza y lugar de origen en su cuerpo no deben ser asumidas o naturalizadas como rasgos de la segmentación socioocupacional, ni de la hipersexualidad en la que la sitúan.

\section{Referencias}

Agustín, Laura. 2000. "Trabajar en la industria del sexo”. OFRIM/Suplementos. Publicación especializada de inmigración. Junio. https://www.lauraagustin.com/trabajar-en-la-industria-del-sexo

-. 2005. "New Research Directions: The Cultural Study of Commercial Sex". Sexualities 8 (5): 618-631.

Arango, Luz Gabriela. 2010. “Género e identidad en el trabajo de cuidado”. En Trabajo, identidad y acción colectiva, coordinado por Enrique de la Garza Toledo y Julio César Neffa, 81-108. Madrid: Clacso; Universidad Autónoma Metropolitana-Iztapalapa; Plaza y Valdés.

Ariza, Marina. 2004. “Obreras, sirvientas y prostitutas. Globalización, familia y mercados de trabajos en República Dominicana”. Estudios Sociológicos 001 (XXII): 123-149.

Benería, Lourdes. 2003. Gender, Development, and Globalization. Economics as if all People Mattered. Londres: Routledge.

Brufao Curiel, Pedro. 2008. Prostitución y políticas públicas: entre la reglamentación, la legalización y la abolición. Madrid: Fundación Alternativas. http://www.observatoripalma. org/imgdb/archivo_doc7822.pdf.

Cantarero, Joan. 2007. Los amos de la prostitución en España. Barcelona: Ediciones B.

Castells, Manuel. 2001. El poder de la identidad. Vol. II de La era de la información: economía, sociedad y cultura. Ciudad de México: Siglo XXI.

Castles, Stephen y Mark J. Miller. 2004. La era de la migración. Movimientos internacionales de población en el mundo moderno. Ciudad de México: Conocer para Decidir; Fundación Nacional Colosio; Universidad Autónoma de Zacatecas; Miguel Ángel Porrúa; Secretaría de Gobierno - Instituto Nacional de Migración.

Cepal. 2003a. El mapa migratorio de América Latina y el Caribe, las mujeres y el género. Serie Población y Desarrollo 44. Santiago de Chile: Cepal.

-. 2003b. La trata de mujeres: sus conexiones y desconexiones con la migración y los derechos humanos. Serie Población y Desarrollo 39. Santiago de Chile: Cepal.

Corso, Carla. 2004. "Desde dentro: los clientes vistos por una prostituta”. En Osborne 2004, 121-134.

De la Garza, Enrique. 2000. “La construcción socioeconómica del mercado de trabajo y la reestructuración productiva en México”. En Reestructuración productiva, mercado de trabajo y 
sindicatos en América Latina, compilado por Enrique de la Garza Toledo, 11-48. Buenos Aires: Clacso; ASDI. http://biblioteca.clacso.edu.ar/clacso/gt/20101108023254/garza5.pdf.

Guasch, Oscar. 1993. "Para una sociología de la sexualidad”. Reis 64: 105-121.

Hill Collins, Patricia. 2000. Black Feminist Thought: Knowledge, Consciousness and the Politics of Empowerment. Londres; Nueva York: Routledge.

Hirata, Helena y Nadya Araujo Guimarães. 2012. Introducción a Cuidado e cuidadoras. As várias faces do trabalho do care, organizado por Helena Hirata y Nadya Araujo Guimarães, 1-11. São Paulo: Atlas.

Hurtado Saa, Teodora. 2011. "Mujeres, negras e inmigrantes construyendo la ocupación de 'proveedoras' de servicios afectivos y 'vendedoras' de bienes erótico-amorosos en los espacios transnacionales”. Tesis doctoral en Estudios Sociales, línea de especialización en Estudios Laborales, Universidad Autónoma Metropolitana, Iztapalapa.

-. 2013a. "Del paradigma higienista a las teorías de la interseccionalidad y la construcción social de la ocupación de las trabajadoras sexuales”. La Manzana de la Discordia 8 (1): 7-22.

-. 2013b. "Mercados globales del cuidado parte de la nueva división internacional del trabajo femenino”. GénEros 12 (1): 113-138.

—. 2014. "Análisis de la relación entre género y sexualidad a partir del estudio de la nueva división internacional del trabajo femenino”. Sociedad y Economía 26: 213-238.

—. 2015. "La prostitución en Colombia: debates en torno al proyecto de Ley 079 de 2013”. Boletina Anual 4: 27-36.

Juliano, Dolores. 2002. La prostitución: el espejo oscuro. Barcelona: Icaria.

—. 2004. "El peso de la discriminación: debates teóricos y fundamentaciones". En Osborne 2004, 43-56.

Kempadoo, Kamala. 1998. “Globalizing Sex Workers’ Rights”. En Global Sex Workers. Rights, Resistance, and Redefinition, editado por Kamala Kempadoo y Jo Deem, 1-28. Londres; Nueva York: Routledge.

—. 2005. "Mudando o debate sobre o tráfico de mulheres”. Cadernos Pagu 25: 55-78.

Lamas, Marta. 2014. “¿Prostitución, trata?”. Consultado el 24 de febrero del 2015. Revista Nexos. http://www.nexoc.com.mx/?p=22354.

Lim, Lin Lean. 2004. "El sector del sexo: la contribución económica de una industria”. En Osborne 2004, 57-84.

-. 2010. "Traite, demande et marché du sexe”. En Le sexe de la mondialisation: genre, classe, race et nouvelle division du travail, editado por Jules Falquet, Helena Hirata, Danièle Kergoat, Brahim Labari, Nicky Le Feuvre y Fatou Sow, 165-184. París: Presse de la Fondation Nationale de Sciences Politiques.

López, Rafael y David Baringo. 2007. “Ciudad y prostitución heterosexual en España: el punto de vista del cliente masculino”. Documentación. Revista de Ciencias Sociales y de Sociología Aplicada 144: 59-74. 
López Riopedre, José. 2010. "Inmigración colombiana y brasileña y prostitución femenina en la ciudad de Lugo: historias de vida de mujeres que ejercen la prostitución en pisos de contactos”. Tesis doctoral, Departamento de Sociología I, Facultad de Ciencias Políticas y Sociología, UNED, Madrid.

Meneses, Carmen. 2003. Perfil de la prostitución callejera. Análisis de una muestra de personas atendidas por APRAMP. Madrid: Universidad Pontificia Comillas.

—. 2007. "Riesgo, vulnerabilidad y prostitución”. Revista de Ciencias Sociales y de Sociología Aplicada 144: 11-36.

Neffa, Julio César. 2010. “La transición desde los 'verdaderos empleos' al trabajo precario”. En Trabajo, identidad y acción colectiva, coordinado por Enrique de la Garza Toledo y Julio César Neffa, 43-80. Madrid: Universidad Autónoma Metropolitana-Iztapalapa; Casa Abierta al Tiempo; Clacso; Plaza y Valdés.

Osborne, Raquel, ed. 2004. Trabajador@s del sexo: derechos, migraciones y tráfico en el siglo $X X I$. Barcelona: Bellaterra-SGU.

Oso, Laura y Marcela Ulloa. 2001. “Tráfico e inmigración femenina desde la voz de las mujeres inmigrantes”. En Tráfico e inmigración de mujeres en España, colombianas y ecuatorianas en los servicios domésticos y sexuales, coordinado por Elena Bonelli Jáudenes y Marcela Ulloa Jiménez, 65-118. Madrid: Apoyo Acsur-Las Segovias.

Parella Rubio, Sonia. 2005. "La segregación laboral y 'vulnerabilidad social' de la mujer inmigrante a partir de la interacción entre clase social, género y etnia”. En Uso de las políticas sociales por las mujeres inmigrantes, editado por Carlota Solé y Lluís Flaquer, 95-136. Madrid: Instituto de la Mujer (Ministerio de Trabajo y Asuntos Sociales).

Piscitelli, Adriana. 2005. "Viagens e sexo on-line: a Internet na geografia do turismo sexual”. Cadernos Pagu 25: 281-326.

—. 2007. "Sexo tropical em um país europeu: migração de brasileiras para a Itália no marco do ‘turismo sexual' internacional”. Estudios Feministas 3 (15): 717-744.

Poyatos i Mata, Glòria. 2008. La prostitución como trabajo autónomo. Barcelona: Bosch. http://biblio.juridicas.unam.mx/revista/pdf/DerechoSocial/14/rb/rb10.pdf.

Sassen, Saskia. 2003. Contrageografías de la globalización. Género y ciudadanía en los circuitos transfronterizos. Madrid: Traficantes de Sueños.

—. 2007. Una sociología de la globalización. Nueva York: Katz.

Soares, Ángelo. 2012. “As emoções du care”. En Cuidado e cuidadoras. As várias faces do trabalho do care, organizado por Helena Hirata y Nadya Araujo Guimarães, 44-59. São Paulo: Atlas.

Tarrius, Alain. 2000. “Leer, describir, interpretar. Las circulaciones migratorias: conveniencia de la noción de ‘territorio circulatorio’. Los nuevos hábitos de la identidad”. Relaciones 21 (83): 39-66.

—. 2002. La mondialisation par le bas. Les nouveaux nómades de l'économie souterraine. París: Balland. 
—. 2010. "Pobres en migración, globalización de las economías y debilitamiento de los modelos integradores: el transnacionalismo migratorio en Europa meridional”. Empiria. Revista de Metodología de Ciencias Sociales 19: 133-156.

Trujillo, Antonio. 2009. Anécdotas de putas. Cuando el placer es un negocio. Barcelona: Styria.

Wade, Peter. 1997. Gente negra, nación mestiza: dinámicas de las identidades raciales en Colombia. Bogotá: Universidad de Antioquia; Instituto Colombiano de Antropología; Siglo del Hombre; Ediciones Uniandes. 